\title{
Islamic Perspectives on Social Work Practice
}

Social work practice in most Islamic and developing countries has followed the western model in the belief that professional practice is universal. After fifty years of social work practice in these countries, however, we find that this model has largely failed due to its exclusion of religious values and spiritual aspects. During the last decade, western professionals realized that the inefficacy of social work practice was due to its avoidance of spiritual and religious aspects in theory and methodology.

The conceptional scientific method based on scientific materialism has not provided a comprehensive study of humanity and society, for its dependence on the senses as the sole source of knowledge meant that revelation-derived knowledge was seen as unimportant. Scientific methodology must be reviewed and reoriented so that it depends on revelation and sense experience as sources of knowledge. As such, the Islamic reorientation of both the social sciences and professions will be necessary during the process of establishing models for sciences based on scientific methodology with regard to revelation as a source of knowledge.

The research problem deals with how to reorient social work practice from an Islamic viewpoint. To achieve this, the Islamic views on five main aspects must be considered: human nature; divine laws governing individual behavior and social organization; causes of individual and social problems; social welfare systems; and practice theory.

The Islamization of knowledge methodology of Ismā'îl al Fārūqī was used. It has three main elements: to a) review modern sciences, analyze their background, and evaluate their strengths and weaknesses from the Islamic view; b) understand and study scholarly contributions based on Muslim scholars' understanding of the Qur'an and Sunnah; and c) join the Islamic view and modern science outputs into one integrated system.

The methodology followed was: a) a verse-by-verse review of the Qur'an to identify key elements related to the research questions. Next, the interpretation of selected verses was located in authoritative tafsir texts; b) al Bukhārī's hadith compilation was reviewed in the same fashion. Explanations of selected hadiths were also sought in Ibn Hajar; c) classical and modern Islamic scholarly writings were reviewed to identify relevant contributions to the research; d) a review of modern social science literature was made for each research question. This was followed by a critical evaluation of modern theories and concepts from the Islamic view (generated in the previous phase of the study); e) based on the evaluation's results, an attempt was made to integrate what was worthwhile in modern scholarship with the broader parameters of the Islamic 
view; and $f$ ) the conclusions were subjected to evaluation by specialists in the Islamic sciences, with corrections duly made.

The research findings are as follows:

1. The detrimental effects of secularized social sciences on social welfare programs and social work practice in Muslim countries were shown clearly.

2. Spiritual and religious dimensions in research and practice should be reinstated as legitimate aspects of theory and intervention.

3. The most important factor in understanding human behavior is one's relationship with his/her Creator, which affects all aspects of life.

4. To the extent that an individual holds to the correct belief system and takes it to heart, he/she will be less prone to personal problems.

5. The basic function of Muslim society is to help preserve the purity of an individual's fittrah (nature).

6. The social welfare system, like all other subsystems in Muslim society, has a mission to fulfill: achieving the purposes of the Shari'ah.

7. Practice theory should be fully attuned to the needs of relevant Islamic views. Spiritual aspects should receive their due place in assessing clients' problems. Intervention strategies should address clients' worldly concerns and improve their spiritual life.

8. The basic strategy of spiritual development aims at helping clients achieve better control over their lives and instincts. Prayers, good deeds, and remembrance of God may help achieve these goals.

9. Such implications are far-reaching for theory, practice, research, and education. A new paradigm seems to be evolving. Social workers and social work educators must reorient their approaches and methods.

10. Schools of social work have a great responsibility, for curricula must be reconstructed to reflect the Islamic view, textbooks expressing the new insights must be written, and teachers need to be retrained.

Afaf Al-Dabbagh Women's Faculty of Social Work Imam Muhammad ibn Saud University Riyadh, Saudi Arabia 